\title{
$\mathrm{BMC}$ ear, nose and throat disorders reviewer acknowledgment 2015
}

Elaine Zhang

\section{Contributing reviewers}

The editors of BMC Ear, Nose and Throat Disorders would like to thank all our reviewers who have contributed to the journal in Volume 15 (2015).

$\begin{array}{lll}\text { Abraham Alabi } & \text { Hasantha Gunasekera } & \text { Bolajoko O. Olusanya } \\ \text { Gabon } & \text { Australia } & \text { Nigeria } \\ \text { Stephen Ball } & \text { Hiroaki Ichijo } & \text { Vijay Pothula } \\ \text { UK } & \text { Japan } & \text { UK } \\ \text { Duncan Bowyer } & \text { Steve Izzat } & \text { James Ramsden } \\ \text { France } & \text { UK } & \text { UK } \\ \text { Jean-Francois Chenot } & \text { Sue Jones } & \text { Baskaran Ranganathan } \\ \text { Germany } & \text { UK } & \text { UK } \\ \text { Paul Counter } & \text { Seung-Han Lee } & \text { Julie Schneider } \\ \text { UK } & \text { Korea, South } & \text { Australia } \\ \text { Robin Criter } & \text { Avril Mansfield } & \text { Laura Tod } \\ \text { USA } & \text { Canada } & \text { UK } \\ \text { Osama Dessouky } & \text { Jan Matthys } & \text { Matthew Trotter } \\ \text { UK } & \text { Belgium } & \text { France } \\ \text { Richard Dowell } & \text { Omar Mirza } & \text { Laura Warner } \\ \text { Australia } & \text { UK } & \text { UK } \\ \text { Ronald Eccles } & \text { Oke Okonkwo } & \text { Brian Westerberg } \\ \text { UK } & \text { UK } & \text { Canada } \\ \text { Thoorlene Egerton } & \text { Okechukwu Okonkwo } & \\ \text { Norway } & \text { UK } & \\ \text { Gregory Grillone } & \text { Folu Ologe } & \\ \text { USA } & \text { Nigeria } & \end{array}$

